\title{
MANAGEMENT PRACTICES
}

Management practice in hospital medicine refers to program/medical group development and growth, practice management, contract negotiation, performance measurement and financial analysis. Hospitalists require fundamental management skills to enhance their individual success, and to facilitate growth and stability of their hospital medicine groups and institutions in which they practice. Hospitals increasingly need physician leaders with management skills to improve operational efficiency and meet other institutional needs. Hospitalists must acquire and maintain management skills that allow them to define their role and value, create a strategic plan for practice growth, anticipate and respond to change, and achieve financial success.

\section{KNOWLEDGE}

Hospitalists should be able to:

- Describe different models of physician compensation and incentives.

- Explain the impact of third-party payer contracts on hospital reimbursement.

- Discuss the potential impact of Pay for Performance initiatives on patient care, and expectations for individual hospitalists and hospital medicine groups.

- Describe Federal statutory restrictions on physicians contracting with hospitals, third-party payers and group practices.

- Describe the impact of medication formularies, utilization review requirements, third party payer contracts and other policies impacting patient care.

- Describe required system improvements needed to meet new healthcare legislation or public health guidelines.

- Describe the personnel file, its contents and usage.

- Define the role and value of hospitalists and hospital medicine programs.

- Explain advantages and disadvantages of utilizing physician extenders in a hospital medicine practice.

- Describe the necessary elements for effective and compliant billing, coding, and revenue capture.

- Define commonly used hospital financial terminology, including but not limited to procedure codes, relative value units (RVUs), direct and indirect costs, average length of stay, and case mix index.

- Define the components of a useful financial report.

\section{SKILLS}

Hospitalists should be able to:

- Apply basic accounting practices to track financial performance and develop a practice budget.

- Develop practice staffing arrangements and schedules.

- Market the hospital medicine program.

- Develop job descriptions for physician and non-physician employees to facilitate accountability and professional development.

- Develop strategies for recruiting and retaining hospitalists.

- Conduct or participate in performance reviews for physician and non-physician staff.

- Negotiate effectively with physicians, medical practices, hospitals, and third party payers.

- Interpret hospital generated reports on individual and group performance.

- Assess satisfaction of community physicians, patients, nurses and other user groups.

- Develop strategic planning processes to meet individual and group goals and establish accountability.

- Develop business plans to facilitate growth of the practice.

- Prepare an annual review of program performance for the hospital executive team.

- Demonstrate teamwork, organization, and leadership skills.

\section{ATTITUDES}

Hospitalists should be able to:

- Lead by example.

- Recognize the importance of routine critical analysis of all aspects of practice operations to optimize efficiency, quality and efficacy.

- Recognize the importance of meeting or exceeding customer and colleague expectations.

- Recognize the importance of best management practice.

- Recognize the importance of marketing and public relations to foster sustainable practice growth. 